\title{
Isolated absence of right pulmonary artery in a 4-year old child: a case report
}

\author{
Abate Yeshidinber \\ Weldetsadik \\ Yemisrach Mekonnen Asfaw \\ Atnafu Mekonnen Tekleab \\ Department of Pediatrics and \\ Child Health, Saint Paul's Hospital \\ Millennium Medical College, Addis \\ Ababa, Ethiopia
}

This article was published in the following Dove Press journal: International Medical Case Reports Journal

\begin{abstract}
Isolated unilateral absence of the pulmonary artery is a rare anomaly with congenital absence of the left or right pulmonary artery in the absence of other cardiac malformation, and diagnosis is usually made during adolescence. We report a 4-year old male child with isolated absence of the right pulmonary artery, who presented with recurrent chest infection and wheezing since infancy.
\end{abstract}

Keywords: pulmonary artery, child, wheeze, chest infection, Ethiopia

\section{Case presentation}

A 4-year old male child was referred to our hospital (St Paul's Hospital Millennium Medical College located in Addis Ababa, Ethiopia) from a district hospital for further evaluation of recurrent chest infection and wheezing in 2018. He was admitted to the referring hospital eight times for chest infection in the first 2 years of his age. The first admission happened at the age of 2 weeks. Cough, fast breathing, and wheezing were the main presenting symptoms during the exacerbations. At each admission, he was treated with parenteral antibiotics and bronchodilators and was discharged from the hospital after he got improvement. He was apparently healthy in between the episodes of the respiratory illness. He did not have history of chocking episodes. He was delivered in a hospital at term, and pregnancy was uneventful. He had optimal development and was a kindergarten student at the time of writing this report.

On examination, he was not in respiratory distress and SPO2 was 94\%-96\% with room air. He weighed $14 \mathrm{~kg}$, with a height of $106 \mathrm{~cm}$ (his anthropometric indices lie above -2 SD except his weight-for-height which lies between -2 and -3 SD). Chest examination revealed trachea shifting to the right side, decreased air entry over the right lung field, and relative dullness over the same area. Cardiac auscultation revealed normal heart sounds with regular rate and rhythm with no gallop. He was alert and playful, having good interaction during the examination.

Basic laboratory examinations were within normal limits, and HIV status was negative. Chest X-ray showed hyperinflated left lung and reduced right lung volume with decreased vascularity and trachea shifted to the right (Figure 1).

Echocardiography demonstrated absence of the right pulmonary artery with no other cardiac lesion (Figure 2). Subsequent computed tomography (CT) scan also showed hypoplastic right lung with absent right pulmonary artery (Figure 3).

The case was evaluated by a team comprising pediatrician, pediatric pulmonologist, and cardiologist, and the team decided to follow the child regularly. orrespondence: Atnafu Mekonnen Tekleab

Department of Pediatrics and Child Health, Saint Paul's Hospital Millennium Medical College, PO Box I27I, Gulele

Sub City, Addis Ababa, Ethiopia

Tel +25 I 91 I34 660 I

Email atnemekonnen@yahoo.com 


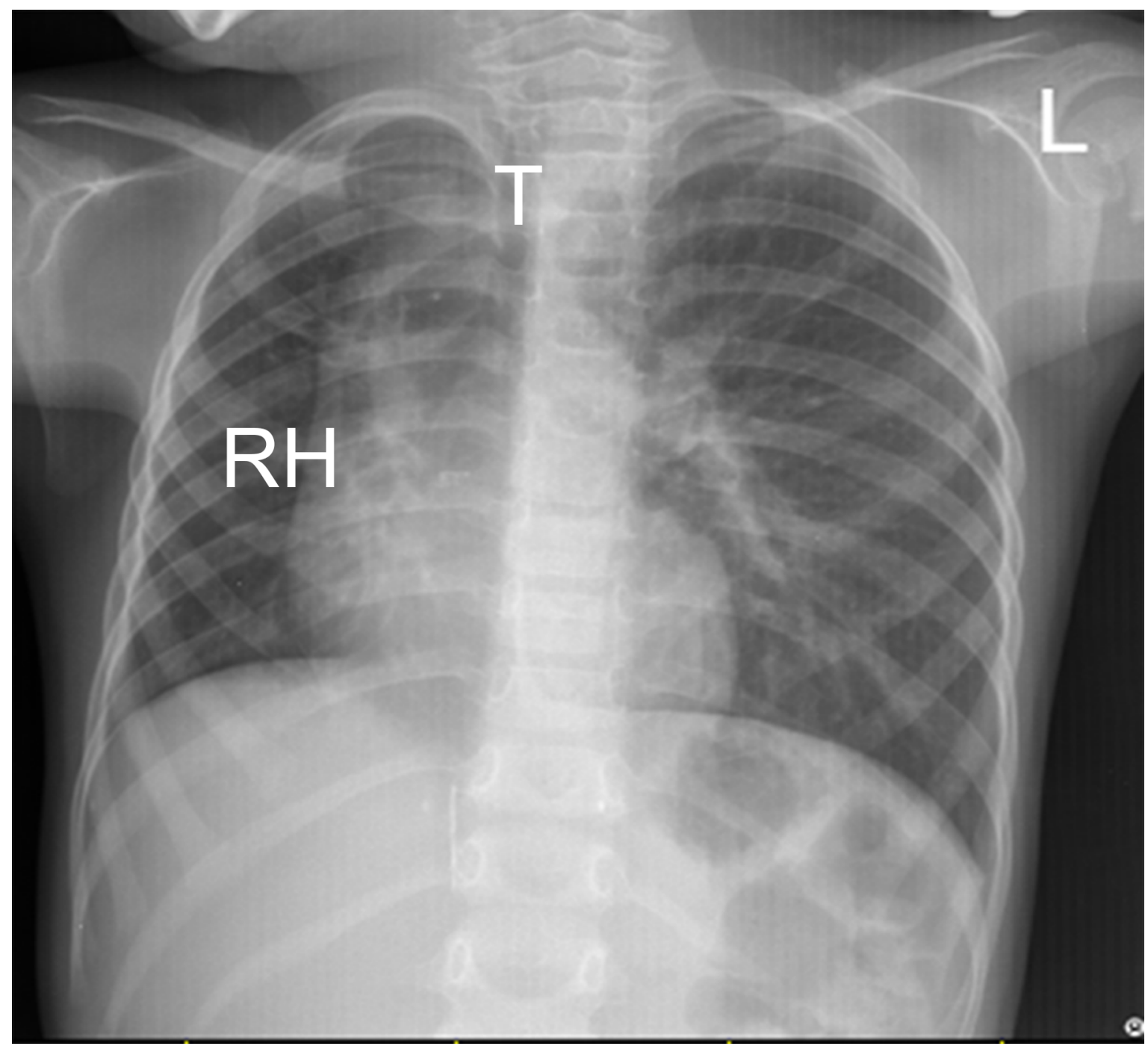

Figure I Posteroanterior chest radiograph showing hyperinflated left lung with reduced right lung volume.

Note: There is also decreased vascularity and hilum not well visualized on the right hemithorax (RH).

Abbreviations: L, left; T, trachea, $\mathrm{RH}$, right hilum.

\section{Discussion}

Unilateral absence of pulmonary artery (UAPA) is congenital absence of the left or right pulmonary artery caused by involution of the proximal sixth aortic arch with persistence of intrapulmonary part to the distal sixth aortic arch. As a result, "proximal interruption of pulmonary artery" has been suggested as a preferred term. ${ }^{1,2}$

UAPA was first described in 1886 and is a rare anomaly with prevalence in the general population ranging from 1 in 200,000 to 1 in 300,000. It rarely presents as an isolated lesion and is more commonly associated with other heart defects. Associated defects include patent ductus arteriosus, tetralogy of Fallot, atrial septal defect, aortic coarctation, truncus arteriosus, and pulmonary atresia. Collaterals to the affected side commonly arise from bronchial arteries, but may also arise from intercostal, subclavian, and rarely coronary arteries. ${ }^{1-3}$

Common presenting symptoms include recurrent respiratory infections, dyspnea, exercise intolerance, hemoptysis, chest pain, and rarely wheezing. Diagnosis can also be incidental in an asymptomatic child. Infants may present with pulmonary hypertension (PHT) and congestive heart failure, whereas hemoptysis is the commonest manifestation in adults. ${ }^{1,2,-7}$ Though there is a recent report of neonatal diagnosis of UAPA, ${ }^{8}$ diagnosis is usually made during adolescence (median age of 14 years), and risk of PHT, hemoptysis, and death significantly increases with age. ${ }^{2,5}$

The mechanism(s) for recurrent pneumonia include hypoperfusion with poor blood flow and decreased inflammatory 

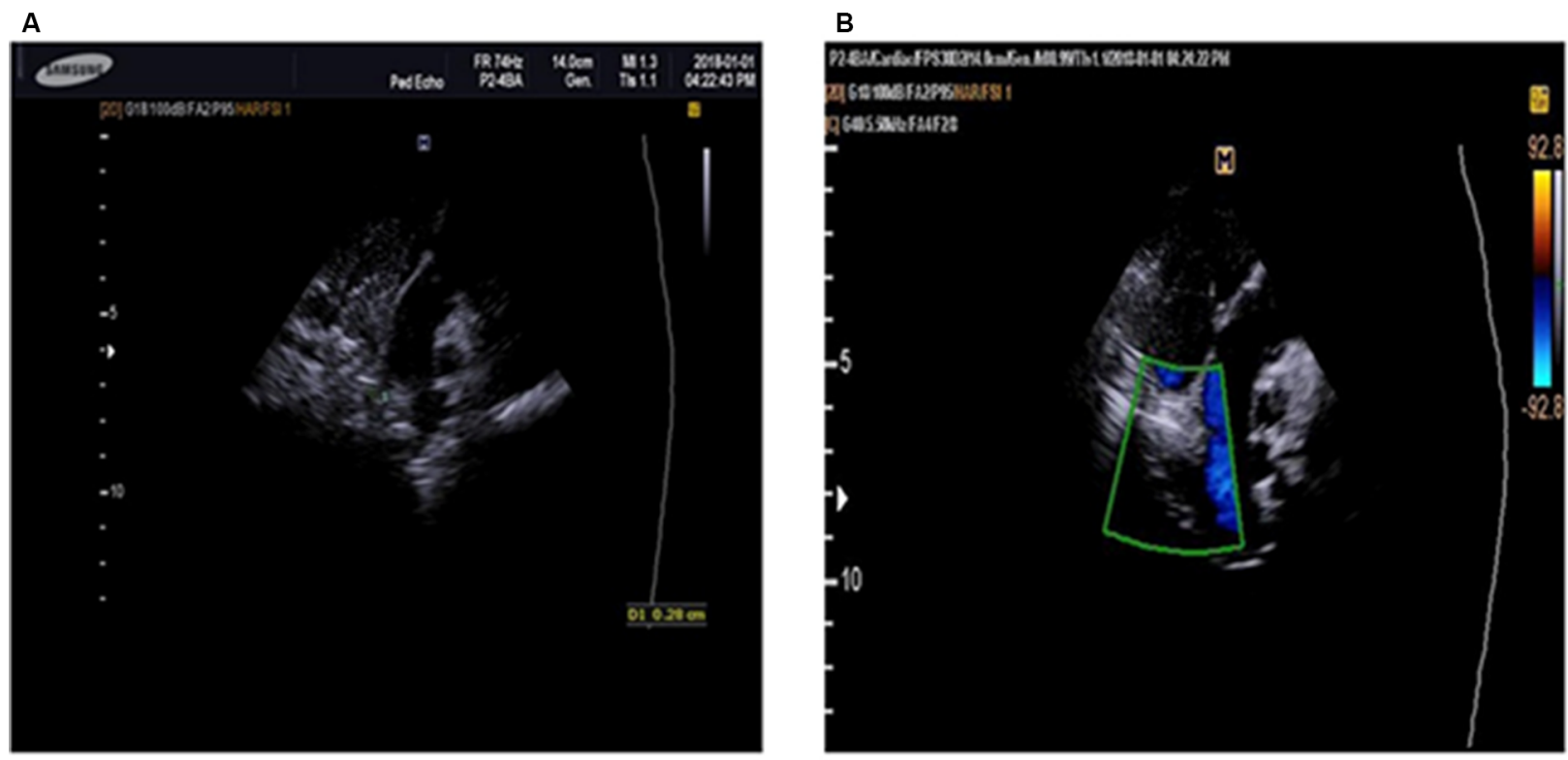

Figure 2 Transthoracic echocardiogram parasternal short axis view.

Notes: (A and B) Transthoracic echocardiogram. (A) (2D mode) in parasternal short axis view demonstrating absence of the right pulmonary artery with main pulmonary artery continuing as left pulmonary artery. (B) (Color flow mode) shows a parasternal short axis view demonstrating presence of flow only through main pulmonary artery and left pulmonary artery.

cell migration, impaired ciliary function, ventilation-perfusion mismatch, alveolar hypocapnea with poor mucosal defense, and protease-antiprotease imbalance. ${ }^{1,2}$

Diagnosis of UAPA is based on a complete history, physical examination, and imaging. Absent pulmonary artery usually causes secondary lung hypoplasia, as in our case, and examination reveals asymmetrical chest with abnormal breath sounds on the affected side. Chest X-ray demonstrates reduction in the volume of hemithorax, elevation in the diaphragm, reduced intercostal spaces, and mediastinal shift to the same side. UAPA should also be suspected in an asymptomatic child with suggestive chest X-ray. ${ }^{1,9}$

Echocardiography, CT of the chest, and magnetic resonant imaging can give the diagnosis with certainty, and invasive procedures including angiography are rarely performed except for intervention or to screen for complications; ventilation-perfusion scan is not necessary for diagnosis. ${ }^{1,10}$

Thrombotic embolus of pulmonary artery, anomalous venous drainage of the right lung into the inferior vena cava (Scimitar syndrome), and Swyer-James syndrome should be considered in the differential and should be ruled out. ${ }^{9}$

Therapeutic strategies for UAPA remain unclear. Presence or absence of complication, pulmonary artery anatomy, associated aortopulmonary collaterals, cardiovascular anomalies, and PHT guide the decision to treat. Regular follow-up is all that the child needs if she/he has normal cardiopulmonary function. Most recommend treatment for the small number of patients with hemoptysis, recurrent respiratory tract infection, or PHT. Treatment options include revascularization, pulmonary vasodilator therapy for PHT, partial or total pneumonectomy, primary or staged pulmonary artery anastomosis, and embolization of collateral hemorrhage..$^{1,1-15}$

The prognosis depends on associated cardiovascular anomalies and the degree of PHT as well as presence or absence of hemoptysis. . $^{1,411}$

\section{Conclusion}

We presented a child with recurrent respiratory symptoms who was finally diagnosed to have isolated unilateral absence of the pulmonary artery (IUAPA). Though IUAPA is a rare condition, it should be considered as a differential diagnosis on a child presented with recurrent chest infections and wheezing. Diagnosis can be made based on history, physical examination, chest X-ray, echocardiography, chest CT, and magnetic resonance imaging without employing invasive diagnostic studies. Treatment is unclear and is usually individualized based on symptoms and associated conditions and is decided by expectant medical or surgical approach. The case described on this case report is being followed by a team consisting of a pediatrician, pulmonologist, and cardiologist 



Figure 3 (A-D) Sequential chest CT images demonstrating volume loss of the right hemithorax with shift of the mediastinum toward the right.

Notes: The left lung is hyperinflated and herniated to the right through the anterior mediastinum. The right pulmonary artery is not visualized and the main pulmonary artery is horizontally oriented. The right hilum is small and left hilum is enlarged. The left main pulmonary artery and its division are prominent.

Abbreviations: AA, ascending aorta; CT, computed tomography; DA, descending aorta; IRPA, interrupted (absent) right pulmonary artery; LPA, left pulmonary artery; MPA, main pulmonary artery.

on an outpatient basis. As stated above, therapeutic strategies for IUAPA remain unclear and initiation of treatment should be guided by the presence or absence of cardiac or respiratory complications. Therefore, the team decided to follow the child regularly since currently he does not have the anticipated complications of IUAPA, except the recurrent chest infection which he has had in the past and which was treated.

\section{Ethics statement}

Written informed consent was obtained from the parent of the child to publish this case report. According to the standard of operating procedure of the Institutional Review Board of our college (St Paul's Hospital Millennium Medical College), publishing a case report is exempted from the board review.

\section{Author contributions}

All authors contributed toward data gathering and compilation, drafting and critically revising the paper, gave final approval of the version to be published, and agree to be accountable for all aspects of the work.

\section{Disclosure}

The authors report no conflicts of interest in this work.

\section{References}

1. Kruzliak P, Syamasundar RP, Novak M, Pechanova O, Kovacova G. Unilateral absence of pulmonary artery: pathophysiology, symptoms, diagnosis and current treatment. Arch Cardiovasc Dis. 2013;106(8-9):448-454.

2. Steiropoulos P, Archontogeorgis K, Tzouvelekis A, Ntolios P, Chatzistefanou A, Bouros D. Unilateral pulmonary artery agenesis: a case series. Hippokratia. 2013;17(1):73-76. 
3. Mohan V, Mohan B, Tandon R, et al. Case report of isolated congenital absence of right pulmonary artery with collaterals from coronary circulation. Indian Heart J. 2014;66(2):220-222.

4. Khadir MA, Narayana G, Ramagopal G, Nayar PG. Isolated Hypoplasia of Left Pulmonary Artery with Agenesis of Left Lobe of Thyroid: A Case Report. J Clin Diagn Res. 2016;10(12):SD04-SD05.

5. Koga H, Hidaka T, Miyako K, Suga N, Takahashi N. Age-related clinical characteristics of isolated congenital unilateral absence of a pulmonary artery. Pediatr Cardiol. 2010;31(8):1186-1190.

6. Bockeria LA, Makhachev OA, Khiriev T, Abramyan MA. Congenital isolated unilateral absence of pulmonary artery and variants of collateral blood supply of the ipsilateral lung. Interact Cardiovasc Thorac Surg. 2011;12(3):509-510.

7. Chang Y, Ra SW, Chae EJ, et al. Isolated Right Pulmonary Artery Hypoplasia with Retrograde Blood Flow in a 68-Year Old Man. Tuberc Respir Dis. 2011;71(2):126-133.

8. Raymond A, Pedretti E, Privitera G, Cicero C, Biasucci G. Neonatal diagnosis of isolated absence of the right pulmonary artery: a case report and review of the literature. Ital J Pediatr. 2018;44(1):27.

9. Sunam G, Ceran S, Agenesis PA, Hypoplasia L. Pulmonary Artery Agenesis and Lung Hypoplasia. Eur J Gen Med. 2009;6(4):265-267.
10. Vitiello R, Pisanti C, Pisanti A, Silberbach M. Association of pulmonary artery agenesis and hypoplasia of the lung. Pediatr Pulmonol. 2006;41(9):897-899.

11. Atik E, Tanamati C, Kajita L, Barbero-Marcial M. Isolated unilateral pulmonary artery agenesis: evaluation of natural and long term evolution after corrective surgery. Arq Bras Cardiol. 2006;87(4): $423-428$.

12. Krammoh EK, Bigras JL, Prsa M, Lapierre C, Miró J, Dahdah NS. Therapeutic strategies in children with an isolated unilaterally absent proximal pulmonary artery. Pediatr Cardiol. 2010;31(5):607-610.

13. Zhou Y, Tsauo J, Li Y, Li X. Selective Embolization of Systemic Collaterals for the Treatment of Recurrent Hemoptysis Secondary to the Unilateral Absence of a Pulmonary Artery in a Child. Cardiovasc Intervent Radiol. 2015;38(5):1312-1315.

14. Yanase Y, Watanabe M, Ishikawa N, et al. Revascularization surgery for isolated unilateral absence of the right pulmonary artery. Kyobu Geka. 2013;66(10):898-901.

15. Hiramatsu T, Komori S, Okamura Y, Suzuki H, Takeuchi T, Shibuta S. Surgical correction of isolated unilateral absence of right pulmonary artery. Heart Vessels. 2010; 25(4):353-355.
International Medical Case Reports Journal

\section{Publish your work in this journal}

The International Medical Case Reports Journal is an international, peer-reviewed open-access journal publishing original case reports from all medical specialties. Previously unpublished medical posters are also accepted relating to any area of clinical or preclinical science. Submissions should not normally exceed 2,000 words or

\section{Dovepress}

4 published pages including figures, diagrams and references. The manuscript management system is completely online and includes a very quick and fair peer-review system, which is all easy to use. Visit http://www.dovepress.com/testimonials.php to read real quotes from published authors. 